\title{
Determination of design and operation parameters influence of screw type pelletizer on crumbling and temperature of soybean chaff pellets
}

\author{
A.A. Penzin*, I.Yu. Tatarenko, E.A. Shulzhenko, V.V. Shishkin, and V.S. Usanov
}

FSBSI FSC All-Russian Scientific Research Institute of soybeans, Ignatievskoe highway, 19, 675027

Blagoveshchensk, Amur region, Russia

\begin{abstract}
This article presents the study of significant factors influence on the pelletizing process of soybean chaff. The aim of the research was to determine the operating modes of the screw providing chaff soybean pellets output with a crumbling of not more than $12 \%$ at the optimum pelletizing temperature of $70-80^{\circ} \mathrm{C}$. To study the significant factors influence - such as the flight screw step, the screw rotation speed, chaff moisture - on the process of soybean chaff pelletizing, as well as the optimal values variation of these factors, search experiments were conducted on the screw type laboratory pelleting press XP-3. Regression equations were calculated as a result of the studies, which are adequately describing the influence of significant factors on the output of proper quality pellets; this will allow to develop the technology for chaff compacting in the process of stationary processing of the grain and soybean heap, which allows to reduce the costs of transportation and storage of soybean chaff.
\end{abstract}

\section{Introduction}

In the process of soybean harvesting in the fields there is a lot of waste in the form of soy straw and soybean chaff, which can be used in feeding farm animals and it will perfectly complement the farms' feed base $[1,2]$.

The use of soybean chaff as an alternative to coarse feed in the diets of animals has a positive effect on their productive qualities through the diet enrichment with high-quality protein, which, can reduce the cost of feed production, and as a result, reduce the cost of obtained products [3, 4].

Analysis of soybean harvesting data for 2000-2019 (according to S.P. Prisyazhnaya [5], as well as the information of the laboratory "Mechanization of agricultural crops' harvesting FSBSI FEIM") showed that the chaff output to grain amounts to an average of $45-50 \%$. With an average soybean yield of $13.3 \mathrm{t} / \mathrm{ha}$ in the Amur region for 2020 , chaff output amounted to about 574300 tons.

\footnotetext{
*Corresponding author: amursoja@gmail.com
} 
As a result of soybean chaff analysis on the basis of the FSBI "Agrochemical Service Station "Amuskaya" (October 2017), as well as research by T.A Krasnoshchekova et al., the content of the main chaff nutrients was found: mass fraction of raw protein $-11.7 \%$; crude fat $-4.6 \%$; crude fiber $-36.4 \%$; digestible protein $-47.0 \%$; feed units $-0,6$, which characterizes its feed value [5-7].

Despite its feed value, soybean chaff has a few technological disadvantages: due to its small specific gravity, the cost of its transportation from the field to the farm, further storage and dispensation is very large. In addition, the physical and mechanical properties of soybean chaff are largely dependent on the weather conditions of the harvesting campaign, variety, cultivation technology, etc. $[1,8]$.

One of the ways to solve this problem can be soybean chaff pressing in pellets (pelletizing), which will reduce the cost of its storage and subsequent application in feeding farm animals. At present, there is no technological equipment allowing to carry out this operation to obtain quality feed raw materials considering the variable characteristics of the soybean chaff coming for pressing.

Therefore, the study of soybean chaff pelletizing process on the screw extruder is a relevant area for research and is of interest both to the scientific community and for production as a whole.

As a result of 2016 - 2018 studies, search experiments on briquetting soybean chaff on impact-mechanical press revealed the disadvantages of this pressing method - namely, low briquette density after strapping, high chaff loss and the need to use binders. Based on the research carried out in the FSBSI FEIM in 2019, the conclusion was made about the feasibility of applying a screw type press pelletizer for soybean chaff pelletizing [10].

Pelletizing is formation of solid particles (pellets) of certain sizes $(3-25 \mathrm{~mm})$ with a volume weight of $600-1300 \mathrm{~kg} / \mathrm{m}^{3}$ according to GOST 23513-79 and GOST 22834-87

Chaff processing using this method leads to a decrease in the cost of its storage and transportation and ensures its disinfection due to temperature effects without binders' use.

The aim of the research was to determine the influence of design and operation parameters of screw type pelletizer on soybean chaff crumbling and pelletizing temperature.

To achieve the goal, the following tasks were solved:

1. To conduct a multifactor experiment to obtain mathematical models of soybean chaff pelletizing process on the screw extruder;

2. To study the soybean chaff pelletizing process and determine the operating modes of the laboratory sample of the screw type pelletizer.

The soybean chaff press pelletizer should ensure stable pellets production with any fluctuations in moisture and fractional composition of chaff, depending on the conditions of the harvesting campaign, quality of crops treatment and its contamination with weeds.

\section{Materials and methods}

Analysis of literary sources, results of theoretical and experimental search studies in 2019 allowed to identify significant factors influencing the pelletizing process (table 1) [10].

To determine the varying levels range of significant factors (flight screw step; screw rotation speed and chaff moisture) influencing the soybean chaff pelletizing process, additional search experiments were carried out in 2020 in FSBSI FEIM on the laboratory press pelletizer XP-3 (Figure 1). 


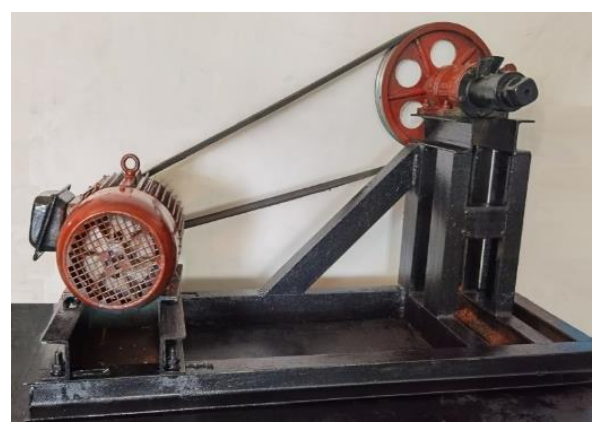

Fig. 1. Laboratory screw press type HR-3.

According to the experimental results, the levels and intervals of varying factors (flight screw step, screw rotation speed and chaff moisture) were reliably determined (table 1) in order to realize the full factor experiment.

Table 1. Factors and levels of their variation.

\begin{tabular}{|c|c|c|c|}
\hline \multirow[b]{2}{*}{ Variation level } & \multicolumn{3}{|c|}{ Factors } \\
\hline & $\begin{array}{c}\text { Flight screw } \\
\text { step t, } \mathbf{m m}\left(\mathrm{x}_{1}\right)\end{array}$ & $\begin{array}{c}\text { Screw rotation } \\
\text { speed } n, r p m\left(x_{2}\right)\end{array}$ & $\begin{array}{c}\text { Soybean chaff } \\
\text { moisture } W, \%\left(x_{3}\right)\end{array}$ \\
\hline+1 & 28 & 400 & 29 \\
\hline 0 & 20 & 250 & 22 \\
\hline-1 & 12 & 100 & 15 \\
\hline Variation interval & 8 & 150 & 7 \\
\hline-1.2154 & 10.3 & 67.7 & 13.5 \\
\hline+1.2154 & 29.7 & 432.3 & 30.5 \\
\hline
\end{tabular}

A full-factor experiment was carried out to optimize the operating modes of the screw type soybean chaff pelletizer.

Planning and processing of the received data was carried out in accordance with the guidelines [11]. Experimental studies were carried out in accordance with generally accepted methods $[11,12]$.

Clean chaff was selected for the study with an average chaff particle size of $50 \mathrm{~mm}$, straight-shaped granulator spinneret with diameters $d_{s}=8.5 \mathrm{~mm}$ was set. Screws with flight steps of $10.3 ; 12 ; 20 ; 28 ; 29 \mathrm{~mm}$ were made in the experimental workshop. The experimental scheme is presented in Figure 2.

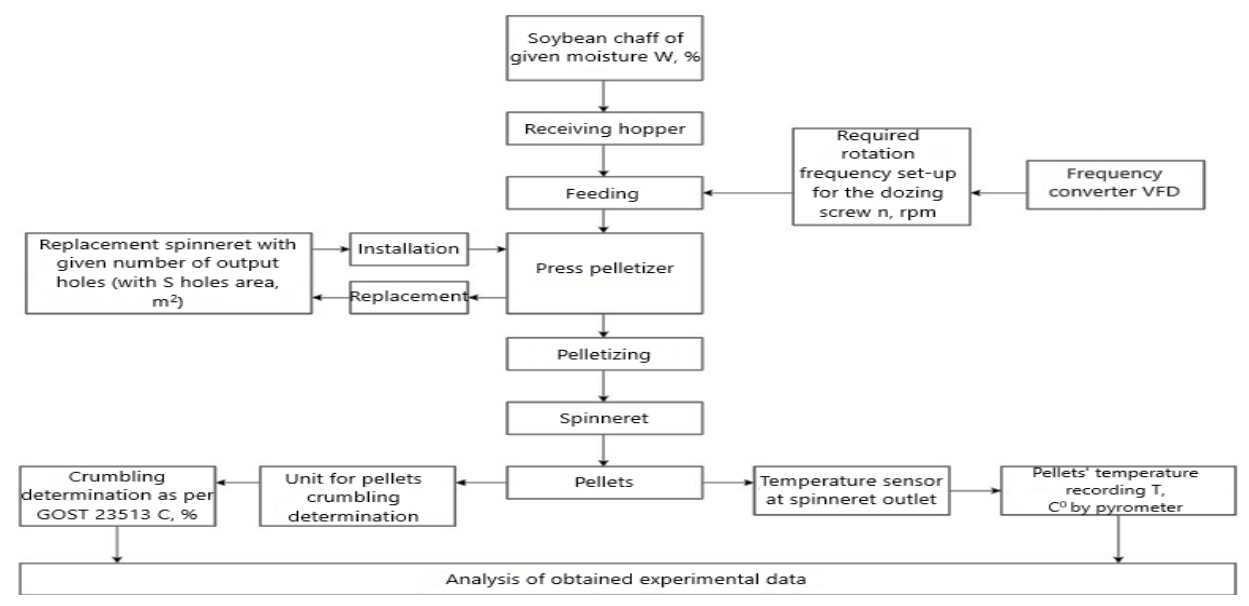

Fig. 2. Experimental scheme. 
Preparation for the experiment on the press pelletizer XP-3 was carried out in the following order: screw installation with the appropriate flight step $\mathrm{t}$; setting the required value of the screw rotation speed using frequency converter $(380 \mathrm{~V}, 3 \mathrm{~kW})$; screw rotation speed control using DT-2235A tachometer.

The chaff of certain moisture level corresponding to the experiment was fed ( $35 \mathrm{~g} / \mathrm{min})$ to the press receiving hopper from the storage hopper. After pelletizing, pellets' density and crumbling were determined. At the same time, the chaff temperature after pelletizing was determined.

Chosen experimental repetition - three-fold, in accordance with the fact that the greatest error for most technical measurements is $\Delta \mathrm{n}= \pm 3 \delta$ [9].

The following were chosen as optimization criteria: pellets crumbling $C, \%\left(U_{c}\right)$, which was calculated in accordance with GOST 23513-79; pellets temperature at the outlet of the pelletizer matrix $\mathrm{T},{ }^{0} \mathrm{C}\left(\mathrm{U}_{\mathrm{t}}\right)$, which was determined by measuring using the Center 350 pyrometer.

Control over pellets' crumbling was determined by a device made in accordance with GOST 23513-79 (Figure 3).

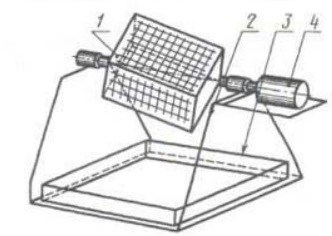

1 - box; 2 - frame; 3 - bath; 4 - drive

Fig. 3. Assembly for determining the pellets' crumbling.

The device is a metal box $300 \times 300 \times 450 \mathrm{~mm}$ covered with mesh and having holes of $1 \times$ $1 \mathrm{~mm}$ dimensions

The box was installed on a frame with a drive mechanism, a bath was installed under it to collect material spilling from the holes of the metal box.

$1 \mathrm{~kg}$ of pellets was taken from the combined sample. Pellets were separated from flour and crumbs and a $500 \mathrm{~g}$ sample was taken, which was placed in the assembly unit. The assembly box with pellets was rotated for 10 minutes at a speed of $50 \mathrm{rpm}$. After that, the pellets were taken out of the box and weighed with an error of $\pm 0.01 \mathrm{~g}$.

Pellets crumbling $(X)$ was calculated in percentage by formula

$$
X=\frac{m-m_{1}}{m} \cdot 100
$$

where $m$ - mass of pellets before the test, $\mathrm{g} ; m_{1}$ - mass of pellets after the test, $\mathrm{g}$.

For the final result of the test, the arithmetic mean of two parallel determinations' results were taken.

Allowed deviations between parallel determinations should not exceed $3 \%$.

The pellet temperature at the outlet of the pelletizer matrix was determined by measuring it using the Center 350 pyrometer.

\section{Results and discussion}

As a result of the experiments, it was established that with the increase in the flight screw step from 12 to $28 \mathrm{~mm}$, the final heating temperature of the granulator shaft was increased 
by $8.3{ }^{\circ} \mathrm{C}$ and pellets crumbling was reduced by $0.94 \%$. Changing the screw rotation speed from 100 to $400 \mathrm{rpm}$ lead to an increase in temperature by $23.3^{\circ} \mathrm{C}$ and a decrease in crumbling by $0.36 \%$. When the chaff moisture changed from 10 to $28 \%$, the shaft temperature decreased by $51.7^{\circ} \mathrm{C}$ and crumbling reduced by $3.2 \%$.

When installing the pelletizing screw in $t=20 \mathrm{~mm}$ step at rotation frequency of $n=250$ rpm, soybean chaff moisture $\mathrm{W}=10 \%$, there was a sharp increase in the unit shaft temperature and pelletizing stoppage, the obtained pellets had a pronounced burning smell.

In connection with the chaff burning process, it was decided to change the lower moisture level from $\mathrm{W}=10$ to $\mathrm{W}=15 \%$. With the combination of these parameters during the operation of the pelletizer, there was an improvement in the pelletizing process (pellets output with crumbling $\mathrm{K}_{\mathrm{p}}=5-6 \%$ in accordance with the requirements of GOST 23513-79) and no chaff burning in the pelletizer shaft, obtaining a better product.

The results of the experiments are presented in table 2.

Table 2. Results of the full-factor experiment

\begin{tabular}{|c|c|c|c|c|c|c|c|c|c|c|c|}
\hline \multirow{2}{*}{ No. } & \multicolumn{3}{|c|}{ Factor levels } & \multicolumn{4}{c|}{ Pellets crumbling, $\%$} & \multicolumn{3}{c|}{ Pellets temperature, ${ }^{\circ} \mathrm{C}$} \\
\cline { 2 - 13 } & $\mathrm{x}_{1}$ & $\mathrm{x}_{2}$ & $\mathrm{x}_{3}$ & $\mathrm{y}_{1,1}$ & $\mathrm{y}_{1,2}$ & $\mathrm{y}_{1,3}$ & $\bar{y}_{1}$ & $\mathrm{y}_{2,1}$ & $\mathrm{y}_{2,2}$ & $\mathrm{y}_{2,3}$ & $\bar{y}_{2}$ \\
\hline 1 & 1 & 1 & 1 & 6.8 & 6 & 6.5 & 6.433 & 47 & 56 & 57 & 53.333 \\
\hline 2 & -1 & 1 & 1 & 3.3 & 4 & 3.7 & 3.666 & 64 & 76 & 79 & 73 \\
\hline 3 & 1 & -1 & 1 & 6.9 & 8 & 6.9 & 7.266 & 45 & 50 & 51 & 48.666 \\
\hline 4 & -1 & -1 & 1 & 9 & 6.7 & 7.5 & 7.733 & 43 & 43 & 54 & 46.666 \\
\hline 5 & 1 & 1 & -1 & 2 & 1.5 & 1.7 & 1.733 & 86 & 93 & 92 & 90.333 \\
\hline 6 & -1 & 1 & -1 & 1.4 & 2.6 & 2 & 2 & 90 & 84 & 89 & 87.666 \\
\hline 7 & 1 & -1 & -1 & 2.9 & 2.2 & 2.7 & 2.6 & 85 & 82 & 77 & 81.333 \\
\hline 8 & -1 & -1 & -1 & 3.8 & 4 & 4.6 & 4.133 & 72 & 63 & 73 & 69.333 \\
\hline 9 & 1.2154 & 0 & 0 & 4 & 4.7 & 4.4 & 4.366 & 68 & 68 & 63 & 66.333 \\
\hline 10 & -1.2154 & 0 & 0 & 4.7 & 4.1 & 4.6 & 4.466 & 63 & 62 & 70 & 65 \\
\hline 11 & 0 & 1.2154 & 0 & 2.8 & 2.5 & 3.2 & 2.833 & 84 & 75 & 77 & 78.666 \\
\hline 12 & 0 & -1.2154 & 0 & 6.1 & 5.7 & 5.3 & 5.7 & 56 & 62 & 65 & 61 \\
\hline 13 & 0 & 0 & 1.2154 & 6.9 & 7.2 & 6.1 & 6.733 & 51 & 54 & 49 & 51.333 \\
\hline 14 & 0 & 0 & -1.2154 & 2.3 & 2.8 & 2.9 & 2.666 & 74 & 86 & 87 & 82.333 \\
\hline 15 & 0 & 0 & 0 & 4.7 & 4.8 & 4.3 & 4.6 & 65 & 66 & 67 & 66 \\
\hline
\end{tabular}

An orthogonal plan of the full-factor experiment was chosen to describe the pelletizing process. As a result of the full-factor experiment results processing, mathematical models (regression equations) were obtained:

for pellets crumbling in encoded values:

$$
\begin{gathered}
U_{c}=\mathrm{b}_{0}-\mathrm{b}_{2} \cdot \mathrm{x}_{2}+\mathrm{b}_{3} \cdot \mathrm{x}_{3}+\mathrm{b}_{12} \cdot \mathrm{x}_{1} \cdot \mathrm{x}_{2}+\mathrm{b}_{13} \cdot \mathrm{x}_{1} \cdot \mathrm{x}_{3}-\mathrm{b}_{23} \cdot \mathrm{x}_{2} \cdot \mathrm{x}_{3}+ \\
\mathrm{b}_{123} \cdot \mathrm{x}_{1} \cdot \mathrm{x}_{2} \cdot \mathrm{x}_{3}
\end{gathered}
$$

in natural values:

$$
\begin{array}{r}
\mathrm{u}_{\mathrm{c}}=2,48472077-0,157564703 \cdot \mathrm{x}_{1}+0,001549953 \cdot \mathrm{x}_{2}+0,27513107 \cdot \mathrm{x}_{3}-0,000175096 \cdot \mathrm{x}_{1} \cdot \mathrm{x}_{2}+ \\
+0,001835327 \cdot \mathrm{x}_{1} \cdot \mathrm{x}_{3}-0,000811506 \cdot \mathrm{x}_{2} \cdot \mathrm{x}_{3}+0,000029265 \cdot \mathrm{x}_{1} \cdot \mathrm{x}_{2} \cdot \mathrm{x}_{3}(3)
\end{array}
$$

for pellets temperature in encoded values:

$\mathrm{U}_{t}=\mathrm{b}_{0}+\mathrm{b}_{2} \cdot \mathrm{x}_{2}-\mathrm{b}_{3} \cdot \mathrm{x}_{3}-\mathrm{b}_{12} \cdot \mathrm{x}_{1} \cdot \mathrm{x}_{2}-\mathrm{b}_{13} \cdot \mathrm{x}_{1} \cdot \mathrm{x}_{3}-\mathrm{b}_{123} \cdot \mathrm{x}_{1} \cdot \mathrm{x}_{2} \cdot \mathrm{x}_{3}+\mathrm{b}_{22} \cdot\left(\mathrm{x}_{2}^{2}-\right.$

in natural values:

$\mathrm{u}_{\mathrm{t}}=75,20358088+1,385663174 \cdot \mathrm{x}_{1}-0,027113196 \cdot \mathrm{x}_{2}-1,397656381 \cdot \mathrm{x}_{3}+0,000808537 *$ $\mathrm{x}_{1} \cdot \mathrm{x}_{2}+0,000190873 \cdot \mathrm{x}_{1} \cdot \mathrm{x}_{2} \cdot \mathrm{x}_{3}-0,024454324 \cdot \mathrm{x}_{1} \cdot \mathrm{x}_{3}+0,003817467 \cdot \mathrm{x}_{2} \cdot \mathrm{x}_{3}$ 
The full-factor experiment resulted in regression equations $1-5$, which relate factor levels to process output. Only statically significant regression coefficients are included in these equations. The resulting regression equations have been tested for adequacy by Fisher's criterion. Obtained inadequacy dispersions $S_{\text {aд }}^{2}$ do not exceed the results reproducibility dispersion $S_{(y)}^{2}$ by more than $\mathrm{F}_{\mathrm{t}}$ times $(2,27)$ where $\mathrm{F}_{\mathrm{t}}$ - Fisher criterion [8] for the selected level of significance. Therefore, it can be said that the resulting model equations adequately describe the studied processes.

\section{Conclusions}

As a result of the mathematical model construction, the reliable dependence of soybean chaff pellets' crumbling and temperature was established on such factors as: flight screw step, screw rotation speed, initial chaff moisture. According to the calculation data with the use of obtained mathematical models, at a fixed average value of the flight screw step of 20 $\mathrm{mm}$ (as the factor least influencing optimization parameters) and average screw rotation frequency value of $250 \mathrm{rpm}$, the fed soybean chaff moisture can vary from 14.6 to $19.9 \%$. With increasing the screw rotation speed to $400 \mathrm{rpm}^{-1}$, fed soybean chaff moisture can vary from 20 to $25.5 \%$. These operating parameters of the soybean chaff laboratory pelletizer will ensure the pellets output with crumbling not higher than $12 \%$ according to GOST $23513-79$ at the optimal temperature of $70-80^{\circ} \mathrm{C}$.

\section{References}

1. S. Rubem, B. Walter, W. Márcio, Journal of the Brazilian Association of Agricultural Engineering, 35(6), 1053 (2015)

2. I.M. Prisyazhnaya, New science in the new world: philosophical, socio-economic, cultural understanding. International Center for Scientific Partnership "New Science", 188 (2019)

3. V.R. Plakhtyukova, Collection of scientific works of the All-Russian Research Institute of Sheep and Goat Production, 2(9), 208 (2016)

4. I.M. Prisyazhnaya, Process improvement of of threshing, separation and transportation to increase the quality of seeds in soybean mechanized harvesting, 192 (2018)

5. S.P. Prisyazhnaya, Improvement of chaff collection technology with grinding and straw spreading during soybean mechanized harvesting, 202 (2013)

6. T.A. Krasnoshchekova, Normed feeding of farm animals, 188 (2011)

7. V.V. Mikhalev, E.A. Shulzhenko, Bulletin of Science and Practice, 4(8), 90 (2018)

8. S.P. Prisyazhnaya, M.M. Prisyazhny, A.P. Dykin, Bulletin of the Far Eastern State Agrarian University, 110 (2007)

9. A.V. Burmaga, E.A. Shulzhenko, V.A. Romanenko, Mechanization and electrification of technological processes in agricultural production. Collection of scientific papers, Blagoveshchensk, 91 (2016)

10. A.A. Kuvshinov, Engineering and equipment for villages, 30 (2019)

11. Yu.P. Adler, Planning an experiment in the search for optimal conditions, 93 (1976)

12. S.V. Melnikov, Planning an experiment in research of agricultural processes, 168 (1980) 